\title{
Olhares críticos e estéticas periféricas: a produção de outras margens no cinema brasileiro
}

\author{
Critical views and peripheral aesthetics: the production of other \\ margins in Brazilian cinema
}

\section{FERNANDA SALVO}

Professora adjunta da Universidade Federal do Acre (Ufac)

Professora adjunta da Universidade Federal do Acre (UFAC). Possui pós-doutoramento pelo Programa de Pós-Graduação em Comunicação Social da Pontifícia Universidade Católica de Minas Gerais (PUCMinas). Doutora em Comunicação Social pela Universidade Federal de Minas Gerais (UFMG). Mestre em Comunicação pela Universidade Federal de Minas Gerais. Especialista em Imagens e Culturas Midiáticas pela Universidade Federal de Minas Gerais. Realizou estágio doutoral no exterior junto à Ruhr-Universität Bochum (Bochum, Alemanha). Atualmente, é professora do curso de Jornalismo e do programa de Pósgraduação em Letras: Linguagem e Identidade, da Universidade Federal do Acre (UFAC).

https://orcid.org/0000-00025901-1770

fernandasalvo@hotmail.com

\section{RESUMO}

No presente artigo, refletiremos sobre o discurso estético como via de contestação das relações de dominação e poder na América Latina. Para melhor iluminar tal perspectiva, retomaremos, inicialmente, a contribuição crítica de Quijano (2005) e Barriendos (2019), que caracterizam a matriz de poder eurocêntrica colonial/ moderna e os processos de inferiorização racial e epistêmica que suas operações impuseram sobre os povos colonizados. Logo após, discutiremos como o Cinema Novo articulou uma política das formas contrária à colonização do olhar e do pensamento, alinhando-se às proposições do Modernismo brasileiro, sobretudo, na destinação estética que conferiu à antropofagia cultural. Em seguida, comentaremos o gesto político endereçado por alguns filmes do cinema nacional contemporâneo, na figuração que propõem da alteridade.

Palavras-chave: Cinema

brasileiro; Estéticas periféricas;

Descolonização do olhar.

\section{ABSTRACT}

In this paper we discuss the aesthetic discourse as a way to challenge domination and power relationships in Latin America. To shed light on this perspective we will initially refer to the critical contributions of Quijano (2005) and Barriendos (2019), who characterized the colonial/modern eurocentric power matrix and the racial and epistemic inferiorization processes that their operations imposed on colonized peoples. After that, we discuss how the Cinema Novo articulated a policy of forms that is contrary to the colonization of the view and the thinking, in line with the propositions of Brazilian Modernism, especially in the aesthetic destination it gave to cultural anthropophagy. Finally, we will comment on the political gestures addressed by some movies of contemporary Brazilian cinema, in their proposed figuration of otherness.

\section{Keywords: Brazilian cinema;}

Peripheral aesthetics; Decolonization of the View. 


\section{HERANÇAS HISTÓRICAS NA AMÉRICA LATINA: PERSPECTIVAS CRÍTICAS}

A violência moral e material inerente ao processo colonizador na América Latina continua sendo aspecto central quando se pretende empreender uma revisão crítica das suas heranças históricas. No horizonte de pensadores que se dedicam à análise das relações de poder nas sociedades latinas (QUIJANO, 2005; BARRIENDOS, 2019, SANTOS, 2019) permanece a questão fundadora da chegada ao Continente de católicos europeus que, autorizados por bulas papais, sob o pretexto de propalar a fé e dilatar territórios, acabaram por promover o "descobrimento" do Outro: encontro de alteridades que levou à quase destruição dos povos originários que habitavam as terras do Sul.

Para esses autores, a expressão máxima da violência imposta pelo dominador caracterizouse pela negação completa do reconhecimento da diferença dos povos colonizados, vislumbrada no apagamento de suas formas de subjetividade, no "epistemicídio" (SANTOS, 2019) e na "invenção" de sua imagem, concebida sob uma perspectiva etnocêntrica.

Aníbal Quijano (2005) escreve que a globalização atual é o desenlace das operações eurocêntricas que culminaram com a formação da América e do capitalismo colonial/moderno, o que implica na necessidade de reconhecimento dos elementos de colonialidade do poder presentes no contexto geopolítico contemporâneo.

O autor afirma que a América se constituiu como "o primeiro espaço-tempo de um padrão de poder de vocação mundial e, desse modo e por isso, como a primeira id-entidade da modernidade" (QUIJANO, 2005, p. 107). Uma das marcas fundacionais desse novo espaçotempo, propõe Quijano, se configurou com a classificação dos povos de acordo com a ideia de raça - que tomou como base supostas estruturas biológicas distintas para determinar o grau de evolução de algumas populações em relação a outras. Tal investida serviu para legitimar as relações de superioridade e inferioridade entre colonizadores e colonizados, convertendo-se na experiência basilar da dominação colonial.

A partir desses critérios, os dominadores classificaram os habitantes da América e, mais tarde, de outras regiões do mundo, produzindo identidades historicamente novas, como "índios", "negros" e "mestiços", mas também redefinindo outras. "Desse modo, raça converteu-se no primeiro critério fundamental para a distribuição da população mundial nos níveis, lugares e papéis na estrutura de poder da nova sociedade. Em outras palavras, no modo básico de classificação social universal da população mundial" (QUIJANO, 2005, p. 108).

As identidades históricas recém-criadas e relegadas a lugares sociais definidos pelo poder, prossegue Quijano, foram submetidas às novas formas de controle e exploração do trabalho, de seus recursos e produtos, o que legitimou práticas como a escravidão. "Uma nova tecnologia 
de dominação/exploração, neste caso, raça/trabalho, articulou-se de maneira que aparecesse como naturalmente associada, o que, até o momento, tem sido excepcionalmente bem-sucedido" (QUIJANO, 2005, p. 109).

Além disso, ao propagar seu domínio por todo o planeta, incorporando diversas regiões terrestres ao "sistema mundo" que se constituía, a Europa produziu novas identidades geoculturais, anulando as concepções culturais dos povos dominados:

\begin{abstract}
A incorporação de tão diversas e heterogêneas histórias culturais a um único mundo dominado pela Europa, significou para esse mundo uma configuração cultural, intelectual, em suma intersubjetiva, equivalente à articulação de todas as formas de controle do trabalho em torno do capital para estabelecer o capitalismo mundial. Com efeito, todas as experiências, histórias, recursos e produtos culturais terminaram também articulados numa só ordem cultural global em torno da hegemonia europeia ou ocidental. Em outras palavras, como parte do novo padrão de poder mundial, a Europa também concentrou sob sua hegemonia o controle de todas as formas de controle da subjetividade, da cultura, e em especial do conhecimento, da produção do conhecimento (QUIJANO, 2005, p. 110).
\end{abstract}

Joaquín Barriendos (2019) observa que os elementos da colonialidade do poder, identificados por Aníbal Quijano, foram fortalecidos por outro aparato definitivo na expansão colonizadora: os processos de inferiorização racial e epistêmica caracterizados pelos diferentes regimes visuais da modernidade/colonialidade.

$\mathrm{Na}$ genealogia que empreende da iconografia ocidental-colonial, Barriendos desvenda as operações de poder subjacentes às imagens criadas pelos dominadores. Com essa mirada crítica, o teórico apresenta os aspectos constitutivos da chamada "colonialidade do ver", conceito criado por ele para definir "a matriz da colonialidade que subjaz a todo regime visual baseado na polarização e inferiorização entre o sujeito que observa e seu objeto (ou sujeito) observado" (BARRIENDOS, 2019, p. 43).

Barriendos ressalta as formas de materialização e reativação desse modo específico de colonialidade, vinculada ao campo das imagens:

\footnotetext{
A permanente permuta dos regimes visuais racializantes produzidos após a "invenção" do "Novo Mundo" (como aquele inaugurado pelos cronistas das Índias em torno do canibalismo e do mau selvagem alheio ao comércio capitalista) é constitutiva da matriz hierárquica de poder a partir da qual operam, na atualidade, a colonialidade do ver e o racismo epistêmico. É por isso que afirmamos que a colonialidade do ver, do mesmo modo que as colonialidades do poder, do ser e do saber, também é constitutiva da modernidade (BARRIENDOS, 2019, p. 42).
}

Na concepção de Barriendos, investigar o campo de atuação da colonialidade do ver garante a ampliação do espectro de análise das maquinarias de racialização erigidas pelo regime visual eurocêntrico. O autor apresenta como exemplo do aparato visual racializador instituído pela 
Europa hegemônica, a cartografia colonial-imperial da alteridade canibal. Para ele, a criação dessa cartografia expansionista proporcionou que territórios antes considerados distantes e misteriosos, mas portadores de imensas riquezas minerais, passassem a ser "metonimicamente falando, a territorialidade simbólica, presencial e material do canibal - isto é, a geografia natural dos caribes" (BARRIENDOS, 2019, p. 46).

O método cartográfico que instituiu simbolicamente o território canibal, continua Barriendos, foi reproduzido em diversas regiões pertencentes ao "Novo Mundo". A instituição de tais espaços, considerados pelos europeus como o ambiente ontológico de seres monstruosos e abjetos, serviu para justificar o processo civilizatório e as expedições escravistas.

Na opinião de Barriendos, a cartografia da alteridade canibal no Novo Mundo converteuse numa das expressões mais genuínas da colonialidade do ver, erigida em plena sintonia com o sistema eurocêntrico, mercantil-capitalista e racializador, determinante da geopolítica instaurada no século XVI. O teórico avalia que a colonialidade do ver adquiriu, num arco mais dilatado de tempo, renovadas configurações. Com o passar dos séculos, escreve Barriendos, as práticas racializantes possibilitaram "uma série de superposições, derivações e recombinações heterárquicas, que em sua descontinuidade interconectam o século $X V$ ao século $X X I$, o século XVI ao século XIX etc." (BARRIENDOS, 2019, p. 44).

Em razão disso, Barriendos recomenda que as expressões visuais oriundas da colonialidade/ modernidade produtoras dos processos de inferiorização racial e epistêmica sejam investigadas e contestadas, assim como "todas as outras narrativas e os imaginários racializantes que surgiram em plena modernidade do capitalismo tardio e que permitiram que se encobrisse certa razão intercultural monoepistêmica, em plena era da globalização cultural" (BARRIENDOS, 2019, p. 52).

Apoiados nessas contribuições teóricas partiremos, agora, para o segundo movimento proposto no presente artigo: recuperar algumas matrizes do pensamento crítico brasileiro no campo das artes, que promoveram, durante o século $\mathrm{XX}$, o debate sobre a autonomia cultural do Brasil, por meio de teorizações e criação de objetos estéticos caracterizados por sua potência reflexiva. Mais precisamente, discutiremos como o Cinema Novo articulou uma política das formas contrária à colonização do pensamento, alinhando-se às proposições do Modernismo brasileiro, sobretudo, na destinação estética que conferiu à antropofagia cultural. 


\section{CINEMA NOVO, MODERNISMO, ANTROPOFAGIA: ESTÉTICAS PERIFÉRICAS ANTICOLONIALISTAS}

Shohat e Stam (2006) afirmam que diante do historicismo eurocêntrico, os cineastas do Terceiro Mundo resolveram reescrever suas próprias histórias, contestando as imagens e os imaginários criados pela Europa hegemônica sobre as nações colonizadas.

No Brasil, tal gesto cinematográfico contestatório se consolidou nos anos 1960, com o advento do Cinema Novo. Os realizadores filiados a essa vertente propuseram em seus filmes imagens conformadas por uma perspectiva anticolonialista, "recuperando e reforçando os eventos do passado em um amplo projeto de remapeamento e renomeação" (SHOHAT e STAM, 2006, p. 358).

Dentro dessa concepção, o Cinema Novo produziu obras revisionistas sobre o período colonial escravista do século XVII, mas, igualmente, obras que reexaminaram fenômenos sociais da década de 1960, como as emergentes formas de vida nas grandes cidades. A maior finalidade dos realizadores do Cinema Novo foi ultrapassar o subdesenvolvimento dos países periféricos, impulsionando a descolonização das imagens em movimento. Em razão disso, muitos filmes do período se fizeram portadores de alegorias, metáforas e símbolos - numa recusa à análise racional da realidade, que, no entendimento dos cineastas, havia sido deformada pelos processos de colonização cultural. Isso significou a rejeição da postura mimética praticada pelo cinema brasileiro em relação ao cinema estrangeiro durante décadas, bem como a negação dos procedimentos narrativos hegemônicos.

Shohat e Stam (2006) lembram que os manifestos dos cineastas terceiro-mundistas dos anos 1960 e 1970 preconizavam um cinema independente e antiimperialista. "Os manifestos contrastavam esse novo cinema não apenas com Hollywood, mas também com as tradições comerciais de seus próprios países, que eram vistas como 'burguesas', 'alienadas' e 'colonizadas'" (SHOHAT e STAM, 2006, p. 356). Não por acaso, no Brasil, o principal alvo da crítica cinemanovista foram as chanchadas de entretenimento e os filmes comerciais da Vera Cruz, acusados pelos jovens realizadores de reproduzir dramas burgueses em estilo europeu.

Para os integrantes do Cinema Novo, a luta pela libertação das imagens e da América Latina deveria ser travada nos planos da estética e da política, e, portanto, uma nova concepção cinematográfica deveria ser criada. Com efeito, o Cinema Novo inventou uma linguagem que incorporou o corte seco, a não linearidade narrativa, a luz estourada, a fotografia contrastada e o uso da câmera na mão, investimento que se traduziu na "estética da fome", em que a escassez de recursos foi tomada como força expressiva.

O Cinema Novo elegeu o sertão, as favelas e os subúrbios como sua principal locação. Os diretores pretendiam, a partir dessas ambientações, revelar a verdadeira face social do Brasil. 
"Da articulação desse olhar, esperava-se, viria um paradigma do real brasileiro, um laboratório sociológico, no qual seriam observáveis, in vitro e in vivo, as contradições que organizam o funcionamento do país" (ORICCHIO, 2003, p. 96).

Tal ímpeto criativo explica o surgimento, na extensa filmografia do período, de figuras representativas de classes sociais e de projetos históricos que cifravam as lutas políticas existentes no extracampo. Na encenação se sobressaía o forte recorte dramatúrgico, muitas vezes alegórico, e os personagens representavam situações que por si só se conectavam com a História, como se observa no caso dos personagens migrantes, camponeses, pescadores, moradores de favela e operários ${ }^{[1]}$.

Ao repercutir as imagens do "verdadeiro" Brasil, a geração do Cinema Novo se aproximou das matrizes do pensamento da vanguarda modernista brasileira, da década de 1920. Ambos os movimentos primaram por uma análise crítica da realidade social e propuseram a revisão dos valores intelectuais e artísticos da sociedade. Em comum, a recusa ao colonialismo cultural e o esforço de consolidar as bases de um nacionalismo crítico. Na concepção de Randal Johnson (1982), são nítidos os paralelos entre Modernismo e Cinema Novo:

\footnotetext{
Ambos os movimentos foram reações contra o código dominante nas suas respectivas áreas de significação: o Modernismo contra o Parnasianismo e sua linguagem "bacharelesca, artificial e idealizante" que espelhava a ideologia da estrutura de classe arcaica da sociedade brasileira; o Cinema Novo, contra a chanchada e os filmes "sérios" produzidos em São Paulo (especialmente os da Vera Cruz), os quais refletiam, ambos, uma visão colonizada, idealizada e inconseqüente da realidade brasileira. Os dois movimentos foram tentativas de descolonização da cultura brasileira através da adoção de uma posição de nacionalismo crítico (JOHNSON, 1982, p. 89).
}

Importante destacar, ainda, que tanto modernistas quanto cinemanovistas reagiram de modo semelhante frente às referências estrangeiras na produção de suas obras. Os modernistas foram os primeiros a reconhecer que não seria possível lidar com as origens nacionais esperando encontrar nelas uma suposta pureza primordial, que repelisse as influências externas. Cientes de que as trocas culturais entre "centro" e "periferia" se impunham como inevitáveis, os intelectuais modernistas introduziram o tema da antropofagia (SHOHAT e STAM, 2006). Se a matriz epistêmica colonial/moderna havia criado a imagem dos povos colonizados como canibais monstruosos e abjetos, conforme elucida Barriendos (2019), os modernistas propunham, agora, a inversão do tema colonialista do canibal.

O canibalismo, como crítica à Europa hegemônica, celebrou os valores das culturas indígenas ancestrais, convertendo-se no substrato da criação estética do movimento Modernista:

Os modernistas brasileiros da década de 20 fizeram do motivo do canibalismo a base de uma estética insurgente, ao exigir uma síntese criativa da vanguarda européia e do "canibalismo brasileiro" e propor que as técnicas e informação 
dos países superdesenvolvidos fossem devorados "antropofagicamente". Assim como os índios tupinambás devoravam seus inimigos para se apropriar da sua força, os modernistas insistiam que os artistas e intelectuais brasileiros deveriam digerir os produtos culturais importados para explorá-los como matéria-prima para uma nova síntese, virando a cultura imposta, transformada, contra o colonizador (SHOHAT e STAM, 2006, p. 427).

Mais tarde, nos anos 1960, a estética modernista influenciaria de maneira definitiva o Cinema Novo. Shohat e Stam (2006) lembram que, embora o tema do canibalismo já tivesse circulado entre a própria vanguarda europeia, para os artistas europeus a antropofagia "nunca constituiu um movimento cultural, nunca definiu uma ideologia e nunca causou uma repercussão cultural comparável ao caso brasileiro" (SHOHAT e STAM, 2006, p. 428). Somente no Brasil, escrevem os autores, a metáfora do canibalismo se tornou a base articuladora de um longevo movimento cultural, "desde a primeira Revista de Antropofagia da década de 20, passando pelas especulações de Oswald de Andrade nos anos 50, até a reciclagem pop da metáfora pelos tropicalistas no final dos anos 60" (SHOHAT e STAM, 2006, p. 428).

O poeta e dramaturgo Oswald de Andrade, autor do Manifesto Antropofágico (1928), defendeu uma prática artística nacional e moderna, que propiciasse a volta ao primitivismo e à barbárie como forma de resistência às normas civilizadas, ao pensamento colonizado e à literatura catequizada. Com vistas à reabilitação da cultura nacional, Oswald de Andrade resgatou a filosofia dos povos ancestrais, elaborando "seu manifesto no contexto de transformação do começo do século, quando as referências parnasianas eram hegemônicas" (ALMEIDA, 2002, p. 7).

Ao cunhar o conceito de antropofagia, Oswald de Andrade propôs a "reabilitação do primitivo no homem civilizado, dando ênfase ao mau selvagem, devorador da cultura alheia transformando-a em própria, desestruturando oposições dicotômicas como colonizador/colonizado, civilizado/ bárbaro, natureza/tecnologia" (ALMEIDA, 2002, p. 1). No campo das artes, o autor defendeu a antropofagia de elementos culturais diversos, que deveriam ser assimilados, incorporados e repercutidos numa concepção original, afirmadora da identidade própria.

O Manifesto Antropofágico fazia a reivindicação metafórica do ato ritual dos primeiros indígenas diante do invasor estrangeiro, quando o objetivo era devorar o inimigo para absorver sua potência. Para o pensamento selvagem, a antropofagia é o fundamento da diferença: é por meio da diferença que se evidencia o choque de alteridades - condição de possibilidade para a descoberta do próprio.

Maria Cândida Ferreira Almeida (2002) avalia que a inversão de valores proposta por Oswald de Andrade, ao retomar o pensamento selvagem, pressupõe uma profunda noção anticolonialista e anti-hierárquica, no que diz respeito à produção artística. Com base na antropofagia cultural, o tradicional discurso ressentido do Terceiro Mundo cede lugar ao discurso autodeterminado:

A antropofagia, enquanto conceito, apresenta uma face produtiva, diversa da pura destruição com que costuma aparecer no discurso "civilizado" sobre a "barbárie", que utiliza o ato canibal como signo da violência máxima. Sob a perspectiva oswaldiana e 
selvagem, a antropofagia preconiza uma espécie de transubstanciação na qual aquele que é devorador se altera no devorado (...). A "morte" e "devoração" do outro recria o próprio; dentro desta perspectiva, o discurso ressentido das relações coloniais torna-se discurso produtivo de identidades (ALMEIDA, 2002, p. 4).

Embora o Modernismo tenha sido um movimento cultural brasileiro, suas influências não se limitaram ao âmbito nacional. A antropofagia cultural preconizada por Oswald de Andrade influenciou o projeto criativo de intelectuais e artistas em proporções globais.

Marcia Orell García (2006) destaca a influência que as noções antropofágicas exerceram sobre os cineastas latino-americanos nos anos 1960. Segundo a autora, Oswald de Andrade tinha como proposta devorar culturalmente tudo o que fosse útil e pudesse redundar na produção de uma obra estética nova e original. Tais preceitos, diz Orell García, foram resgatados pelos inquietos cineastas latinos, na produção de uma linguagem própria que se chamou Cinema Novo:

\begin{abstract}
El índio comía al enemigo para adquirir sus poderes, no para alimentarse físicamente. Era algo ritual. Sin duda el Nuevo Cine Latinoamericano es producto de esta antropofagia, por cuanto la mayoría de los realizadores latinoamericanos de esa época, tomaron las influencias del neorealismo italiano, de la nouvelle vague francesa, del free cinema inglés, del cine japonés de Kurosawa y otras no tan definidas, que ensambladas com las manifestaciones nacionales culturales locales, obtuvieron el resultado de aquel lenguaje específico que se llamó Nuevo Cine (GARCÍA, 2006, p. 87).
\end{abstract}

De fato, a metáfora antropofágica foi compartilhada por muitos cineastas dos países periféricos. Esse ritual "oral" de resistência somou-se à política das imagens dos novos cinemas, que primava pela invenção formal como possibilidade para a ação social. Isso porque somente a libertação cultural do Continente e a correlata descolonização de suas imagens permitiria a feitura de um cinema "latino". Glauber Rocha (2004) pontua a questão:

\footnotetext{
Quando se fala de cinema latino, a significação ultrapassa o sentido puramente cinematográfico. A consciência latina começa a se popularizar. A descoberta de que o Brasil, México, Argentina, Peru, Bolívia etc. fazem parte do mesmo bloco de exploração norte-americana e que esta exploração é uma das causas mais profundas do subdesenvolvimento que se concretiza a cada dia que passa, e que, o mais importante, se populariza. A noção de América Latina supera a noção de nacionalismos. Existe um problema comum: a miséria. Existe um objetivo comum: a libertação econômica, política e cultural de fazer um cinema latino. Um cinema empenhado, didático, épico, revolucionário. Um cinema sem fronteiras, de língua e problemas comuns (ROCHA, 2004, p. 83).
}

Muitos diretores ligados aos novos cinemas latinos tomaram a prática cinematográfica como instância de reflexão e crítica. Não por acaso, Glauber Rocha, Fernando Solanas, Octavio Getino e Julio García Espinosa propuseram teorias cinematográficas para os países subdesenvolvidos em elaborações intelectuais, cujas premissas se refletiram nos roteiros dos filmes.

Isso significa que o debate realizado em torno das problemáticas históricas, culturais e políticas da América Latina encontrou ressonância nas encenações fílmicas. A aliança entre teoria 
e prática resultou em criações estético-políticas por meio das quais os cineastas pretenderam influenciar o processo dialético da História.

Glauber Rocha (2004), num de seus mais conhecidos ensaios - Estética da fome, de 1965 - defendeu uma estética em que a violência e o choque das imagens tirassem o espectador de sua zona de conforto, confrontando-o com aquele que seria o nervo exposto da sociedade latina e a trágica originalidade do subdesenvolvimento: a fome e a miséria. Na concepção do cineasta, era necessário dar consciência dessa miséria. Disso resultaria um cinema não sobre a fome, mas nascido dela. Nesse aspecto, a forma do filme seria decisiva.

Com gesto similar ao de Glauber Rocha, os argentinos Fernando Solanas e Octavio Getino escreveram Hacia el tercer cine (1969). O famoso ensaio é a defesa de um cinema comprometido com a libertação da Argentina e da América Latina, a partir de uma terceira via cinematográfica denominada Tercer Cine. O objetivo do Terceiro Cinema consistia em destituir o modelo narrativo de Hollywood, bem como o cinema de autor europeu, que, no entendimento dos cineastas, apresentavam procedimentos estéticos incapazes de abordar as questões latinas.

Os ensaios militantes de Rocha, Solanas e Getino convocavam para "uma revolução tricontinental na política e para uma revolução estética e narrativa na forma do filme" (SHOHAT e STAM, 2006, p. 356). Tais textos traduziram a confluência de pensamentos dos cineastas e teóricos latinos, na década de 1960. Essas intervenções obtiveram grande sintonia com os debates da crítica e muitas produções dos novos cinemas foram premiadas em festivais internacionais. Daquele momento em diante, o mundo não poderia mais ignorar as vozes silenciadas da América Latina.

\section{CONSIDERAÇÕES FINAIS}

Revisar a contribuição de movimentos estéticos que revitalizaram a cultura na América Latina é também um meio de historicizar as lutas decoloniais contemporâneas. A reflexão crítica proposta pelo Cinema Novo já havia incorporado uma ampla carga de reivindicações relativas à invenção de outras estéticas, outras imagens e outros imaginários para posicionar o periférico na História.

O alinhamento do Cinema Novo com o Modernismo está diretamente relacionado à maneira como ambos os movimentos buscaram combater a mentalidade colonial, priorizando a autonomia intelectual do Brasil. A destinação estética que os dois movimentos conferiram à antropofagia, revertendo o tema colonial do canibalismo, revelou a consciência de artistas e intelectuais 
periféricos sobre a necessária adoção de uma política das formas que, libertária, deveria negar o mimetismo às produções estrangeiras, construindo meios que fomentassem a descolonização do olhar e do pensamento. Ao mesmo tempo, a política formal original que empregaram permitiu a contaminação entre linguagem e experiência, tornando possível a abordagem de temas locais, que antes pareciam não merecer ser vistos.

Os procedimentos estéticos inovadores introduzidos por modernistas e cinemanovistas foram capazes de equacionar noções como eu/outro, colonizador/colonizado, centro/margens em proposições que anteciparam questões fundamentais do debate contemporâneo relativo à política das diferenças e à instauração de paradigmas que apontem para novas epistemologias e racionalidades, abertas à valorização das culturas de povos historicamente silenciados.

No cinema brasileiro contemporâneo, os filmes abandonaram a ideia da construção de uma identidade nacional, conforme pensada no passado, mas os realizadores retomaram a questão das margens. Na atualidade, sob diferentes abordagens e variados gestos criativos, os cineastas reiteram o movimento de aproximação com o Outro. Contudo, os procedimentos interpretativos totalizantes e a criação de categorias sociais genéricas que conectavam os personagens com a História foi gradativamente perdendo fôlego ao longo das décadas, devido às mudanças conjunturais que, inevitavelmente, incidiram sobre os procedimentos dos realizadores.

Nos últimos anos, os filmes nacionais reafirmam o interesse pela alteridade, pelo pobre e o marginal, mas buscando novos engajamentos, contando a história dos vencidos a partir de enfoques menores, que exploram as singularidades dos personagens, as vidas comuns e as biografias ordinárias. Essa abordagem singularizante coloca em jogo questões estéticas e políticas fundamentais no cinema brasileiro hoje, inseparáveis dos modos de inscrição da alteridade. As produções recentes têm matizado que a escolha de recursos expressivos e de procedimentos de abordagem é decisiva para uma aparição mais acolhedora da singularidade dos sujeitos filmados.

A retomada do cotidiano e da vida ordinária em alguns filmes brasileiros, a partir dos anos 2000, é reveladora de uma das facetas desse cinema que buscou explorar o recorte menor, as estórias individuais e os universos singulares, em detrimento das generalizações e determinações do contexto. Em muitas narrativas que apresentaram os sujeitos ordinários em seu ambiente e cultura, a cena fílmica tornou-se porosa ao cotidiano, onde estão abrigadas as vinculações afetivas e as potências do viver ${ }^{[2]}$.

Exemplos nesse sentido, de uma escritura fílmica que contribuiu para que algo singular dos personagens e seu mundo viesse compor a encenação, podem ser encontrados nos filmes Avenida Brasília Formosa (Gabriel Mascaro, 2010) e O Céu sobre os ombros (Sergio Borges, 2010). Neles, a força que assume o cotidiano faz as imagens nascerem coladas à experiência. Ambas as narrativas apresentam moradores de periferias das grandes cidades. Nos dois casos, 
estamos diante de não-atores que interpretaram estórias inspiradas livremente em suas vidas reais. Em Avenida Brasília Formosa conhecemos Pirambu, o pescador; Fábio, que é garçom e videomaker amador; Débora, a cabeleireira que pretende chegar ao Big Brother Brasil e Cauan, uma criança em idade escolar. O Céu sobre os ombros, por sua vez, traz para a encenação Lwei, um escritor; Murari, operador de telemarketing, cozinheiro, torcedor de futebol, hare krishna e skatista e Everlyn Barbin que é transexual, professora e prostituta.

Uma das primeiras questões que esses filmes colocam é apresentar personagens pertencentes a universos tão díspares, que se torna difícil enquadra-los sob um olhar unificador. Além disso, a própria estratégia criativa dos filmes, que desliza entre documentário e ficção e permite que os sujeitos filmados interpretem a si mesmos, torna indiscerníveis os limites entre pessoa e personagem, esfumaçando também as fronteiras entre a mise-en-scène fílmica e o cotidiano. Tal recurso de abordagem autoriza que os sujeitos filmados ficcionalizem, inventem a si mesmos e se multipliquem, tornando-se outros, enquanto a duração os acolhe. Essa multiplicação das formas de estar no mundo dificulta os enquadramentos prévios e o estabelecimento de identidades fixas e estereótipos, o que reforça a perspectiva singularizante lançada pelas narrativas.

Por outro lado, a tomada do cotidiano como ponto de vista incide de maneira decisiva sobre a forma dos filmes. As encenações se deixam contaminar pelas situações episódicas da rotina, incorporando seus ritmos, o que resulta em temporalidades lacunares e desamarradas. André Brasil e Cláudia Mesquita (2012) já haviam notado que filmes como Avenida Brasília Formosa e O Céu sobre os ombros são modulados por uma espécie de "modéstia da forma", já que sua escritura se deixa impregnar pelas formas sensíveis do mundo, colocando-se em estreita interseção com o espaço-tempo dos sujeitos filmados.

Como resultado dessa escolha estética, a duração das imagens exacerba a percepção das horas prosaicas, adensando a maneira como os espectadores travam contato visual com os lugares, as coisas e os personagens, adentrando suas casas, escutando seu sotaque, presenciando gestos, atitudes e intensidades, quando, por exemplo, eles soltam os corpos nos forrós, ouvem um hit no rádio ou caminham pelas ruas, desenhando uma cidade. Tais situações reforçam o entendimento de que nos espaços que os sujeitos habitam ordinariamente se inscrevem suas realidades afetivas, suas vinculações a um mundo comum compartilhado, e, sem dúvida, as potências das formas vividas.

Isso significa que em Avenida Brasília Formosa e O Céu sobre os ombros, a escritura, pelo modo como é convocada, contribui para que possamos experimentar os espaços periféricos da cidade de maneira positivada. As formas sensíveis dos filmes convocam outro modo de apreensão da alteridade, diferente daquele disseminado pelas narrativas hegemônicas, que, não raro, promovem uma exposição exótica, turística ou espetacular da vida ordinária. 
Contudo, os espaços nos dois filmes não são construídos de maneira recôndita, como zonas de pureza, esquivadas dos atravessamentos da ordem capitalista e desigual. Os personagens de Avenida Brasília Formosa, por exemplo, são as vítimas do processo de reurbanização e gentrificação na cidade do Recife (PE), que em 2001 deslocou os moradores da Brasília Teimosa (grande favela de palafitas à beira-mar) para um residencial popular, localizado na avenida que dá título ao filme. Na paisagem da orla surgiram enormes torres residências, onde foram instalados os apartamentos mais valorizados da cidade. No filme de Mascaro, essa experiência é retratada pelo olhar dos habitantes da Brasília Formosa. Pirambu, por exemplo, é o pescador que foi viver longe do mar e, agora, prepara suas redes de pesca na área externa do conjunto habitacional.

Já em O Céu sobre os ombros, que se passa na cidade de Belo Horizonte (MG), os sujeitos filmados elaboram o cotidiano como podem: Lwei é um escritor negro, pobre e desempregado que não consegue pagar as contas do filho, mas segue lutando para publicar um livro. Everlyn é uma transexual que divide o tempo entre os estudos e os programas que faz como prostituta, no fim da noite. Já Murari se desdobra entre os empregos que possui como atendente de telemarketing e cozinheiro num restaurante. Tais situações, que enredam os personagens, mostram o quanto o capitalismo desfere seus golpes mais pesados sobre as populações periféricas.

Ao colocar em cena o cotidiano de pessoas marginalizadas pela ordem capitalista, Mascaro e Borges promovem uma remissão ao fora de campo dos filmes, consumando o gesto político das imagens. Cezar Migliorin (2010) já havia destacado essa característica:

Não se trata da busca de uma poética da banalidade, gesto tão caro ao documentário e às artes contemporâneas. Essa escritura no cotidiano permite que façamos a mais difícil das passagens, aquela da experiência cotidiana até os poderes mais organizados e macro-operadores na cidade (MIGLIORIN, 2010, p. 51).

Nos dois filmes, o cotidiano é cerrado, atravessado por múltiplas forças. Há uma face dura que se expõe, denunciando as desigualdades sociais. Todavia, os filmes propõem rearranjos simbólicos, evidenciando que nesse cotidiano, nada simples, os sujeitos filmados resistem, inventando modos de existir. Assim, o cinema recompõe, por meio de suas operações espaçotemporais, as experiências e as vidas.

É preciso lembrar, contudo, que a figuração da alteridade atrelada ao cotidiano foi somente uma das maneiras que os filmes nacionais contemporâneos encontraram para exercer seu gesto contestatório, colocando-se criticamente frente às relações de poder existentes no mundo histórico. Ao lado dessa forma de abordagem surgiram outras tantas, conformadas por estéticas e estilísticas bastante variadas.

Se ao argumento decolonial é cara a assunção de epistemologias e regimes visuais que desafiem a colonialidade do atual padrão de poder mundial, o cinema nacional contemporâneo 
pode contribuir com esse debate, pois muitos filmes recentes se dedicam a criar novas formas de sensibilidade, que reescrevem os modos de vida, os saberes e as culturas de sujeitos historicamente apagados pela matriz eurocêntrica/ocidental.

Diante do reconhecimento das assimetrias de poder entre aqueles que filmam e aqueles que são filmados e das diferenças irredutíveis existentes no mundo social, muitas produções cinematográficas vêm buscando maneiras não de extirpar as diferenças, mas de redimensionálas, por meio da experiência dos filmes.

Tais investimentos estéticos têm sido determinantes na construção de um inventário de imagens periféricas, próprias de seu tempo. Esses engajamentos intensificam a crença na política das imagens, lembrando que os filmes, mais que registrar o presente, são potentes também para construí-lo.

\section{REFERÊNCIAS}

ALMEIDA, M. C. F. Só a antropofagia nos une. In: MATO, Daniel (org.). Estudios y otras prácticas intelectuales latinoamericanas en cultura y poder. CLACSO, Consejo Latinoamericano de Ciencias Sociales, Caracas, Venezuela. p. 1-16. 2002. Disponível:

http://bibliotecavirtual.clacso.org.ar/ar/libros/cultura/ferreira.doc

BARRIENDOS, J. A colonialidade do ver: rumo a um novo diálogo visual interepistêmico. Revista Epistemologias do Sul, v. 3, n.1, p. 38-56, 2019.

BERNARDET, J. C. Trajetória Crítica. SP: Livraria Editora Polis, 1978.

BR ASIL, A.; MESQUITA, C. O meio bebeu o fim, como o mata-borrão bebe a tinta: notas sobre O céu sobre os ombros e Avenida Brasilia Formosa. In: BRANDÃO, A.; JULIANO, D.; LIRA, R. (orgs.). Políticas dos cinemas latino-americanos. SC, Ed. Unisul, 2012. p. 231-248.

GARCÍA, M. O. Las Fuentes del Nuevo Cine Latinoamericano. Ediciones Universitárias de Valparaíso, 2006.

JOHNSON, R. Macunaima: do Modernismo na literatura ao Cinema Novo. SP: T. A. Queiroz, 1982.

LEROUX, L. A Baixada tem, a Baixada filma: a periferia, da representação à autoapresentação. In: SALES, M.; CUNHA P.; LEROUX, L. (orgs.). Cinemas pós-coloniais e periféricos v. 1. Guimarães: Nós por cá todos bem - Associação Cultural. RJ. Edições LCV, 2019. p. 24-40. 
MIGLIORIN, C. 5 x favela - agora por nós mesmos e Avenida Brasilia Formosa: das possibilidades de uma imagem critica. In. Devires - Cinema e Humanidades, BH, v. 7, n. 2, p. 41-55, jun-dez. 2010.

ORICCHIO, L. Z. Cinema de Novo. SP: Liberdade, 2003.

QUIJANO. A. Colonialidade do poder, eurocentrismo e América Latina. In: LANDER, E. (org.). A colonialidade do saber: eurocentrismo e ciências sociais. Perspectivas latino-americanas. Colección Sur Sur, CLACSO, Ciudad Autónoma de Buenos Aires, Argentina. p. 107-130, 2005. Disponível em:

https://edisciplinas.usp.br/pluginfile.php/2591382/mod_resource/content/1/colonialidade_do_saber_ eurocentrismo_ciencias_sociais.pdf

ROCHA, G. Revolução do Cinema Novo. SP: Cosac \& Naify, 2004.

SANTOS, B. S. O fim do império cognitivo. BH: Autêntica, 2019.

SHOHAT, E.; STAM, R. Critica da imagem eurocêntrica. SP: Cosac \& Naify, 2006.

[1] É preciso considerar que as formulações do Cinema Novo já foram objeto de críticas e revisões. São conhecidos os argumentos de Jean-Claude Bernardet (1978), que considerou frágeis as posições políticas do Cinema Novo, pela visão excessivamente globalizante apresentada nas representações de cunho realista crítico. Conforme pontua o autor: “(...) A dinâmica era a revolta que permitia o enfoque global. Deliberadamente uso as palavras vagas — transformação, revolta, etc. - para me referir a esses filmes, devido justamente à pouca precisão política e seu fundo que me parece liberal e populista, apesar dos momentos de radicalismo que aparecem neles” (BERNARDET, 1978, p. 131). Por outro viés, mas expressando visada crítica, o cineasta Haile Gerima afirma que o Cinema Novo "torna-se um imperialista doméstico quando os cineastas se apropriam das histórias negras" (GERIMA apud LEROUX, 2019, p. 27-28). Reconhecemos a importância dessas opiniões, mas não avançaremos na discussão que introduzem, pois extrapolaríamos os objetivos desse trabalho. Aqui, buscaremos revisar a contribuição do Cinema Novo nas rupturas que propôs em relação aos padrões estéticos estrangeiros e europeizados. A intervenção do Cinema Novo é seminal nesse sentido, embora o movimento não tenha se mantido isento de contradições. 
[2] Destacamos algumas produções brasileiras realizadas a partir dos anos 2000, nas quais a presença do cotidiano se faz marcante: O céu de Suely (Karim Aïnouz, 2006); As vilas volantes: o verbo contra o vento (Alexandre Veras, 2006); Morro do Céu (Gustavo Spolidoro, 2008); Viajo porque preciso, volto porque te amo (Marcelo Gomes e Karim Aïnouz, 2009); A falta que me faz (Marília Rocha, 2009); Notas Flanantes (Clarice Campolina, 2009); Transeunte (Eryk Rocha, 2010); Avenida Brasília Formosa (Gabriel Mascaro, 2010); O Céu sobre os Ombros (Sérgio Borges, 2010), entre outros. Embora saibamos que esses filmes obedecem a projetos criativos bastante diversos, há um elemento comum que permite aproximá-los: entre o espaço/ tempo que constroem e os personagens, o cotidiano desponta como mediador. Tal característica se sobressaiu, ainda, em produções mais recentes, tais como Baronesa (Juliana Antunes, 2017); Temporada (André Novais Oliveira, 2019) e No coração do mundo (Gabriel Martins e Maurílio Martins, 2019). 